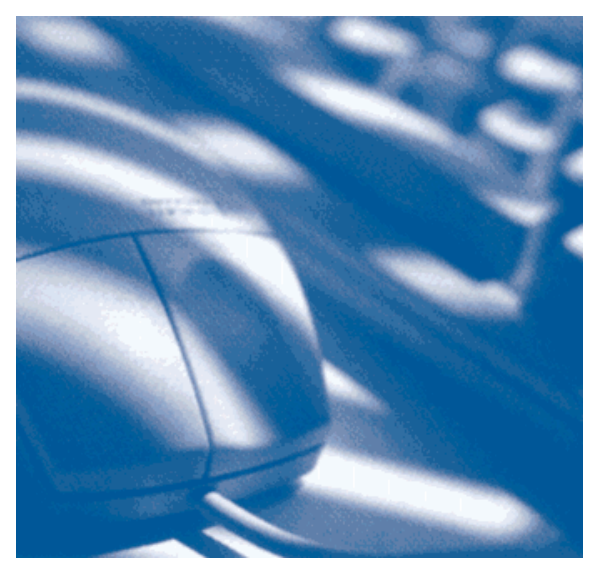

\section{Ask patients which herbal drugs they smoke as well as eat}

To the Editors,

Devoting an entire issue of the journal (September 1999) to alternative medicine is timely because alternative medicine has recently increased in popularity in the United States. The total 1997 out-of-pocket expenditures related to alternative therapies were conservatively estimated at $\$ 27$ billion; at the same time, a $380 \%$ increase was observed in the use of herbal remedies compared with $1990 .^{1}$

\section{Dong quai potentiates the anticoagulant effects of warfarin}

Among the herbal drugs that may give rise to an adverse reaction, dang gui or dong quai (Angelica sinensis) was referred to in two of the articles. $^{2,3}$ Unfortunately, no mention was made in either article of its interaction with warfarin sodium. Warfarin is one of the most commonly prescribed western medicines as an anticoagulant in the management of atrial fibrillation, which is the most common arrhythmia, found in $3.8 \%$ of the population older than 60 years and up to $11 \%$ in persons older than 70 years. ${ }^{4}$ Dong quai potentiates the anticoagulant effect of warfarin.

Another popular and commonly used herbal medicine that potentiates the anticoagulant effect of warfarin is danshen, which is a widely used Chinese herbal drug in cardiology for the treatment of various symptoms of coronary artery disease, including angina pectoris, myocardial infarction, and congestive heart failure. ${ }^{5-7}$ Danshen may be not only taken by mouth but also inhaled. It has become so popular that it has even been incorporated into some Chinese cigarettes. ${ }^{7}$ Therefore, in taking history from a Chinese patient, the physician should not only ask which oral herbal drugs the patient is taking but also what brand of cigarettes he or she smokes. $^{5}$

Tsung 0 Cheng

Division of Cardiology

George Washington University Medical Center 2150 Pennsylvania Ave NW

Washington, DC 20037

References

1 Eisenberg DM, Davis RB, Ettner SL, et al. Trends in alternative medicine use in the United States, 1990-1997: results of a follow-up national survey. JAMA 1998;280:1569-1575.

2 Ko R. Adverse reactions to watch for in patients using herbal remedies. West J Med 1999;171:181-186.

3 Nambiar S, Schwartz RH, Constantino A.

Hypertension in mother and baby linked to ingestion of Chinese herbal medicine [letter]. West J Med 1999; 171:152.

4 Kannel WB, Abbott RD, Savage DD, et al. Epidemiologic features of chronic atrial fibrillation: the Framingham study. N Engl J Med 1982;306:10181022.

5 Cheng TO. Warfarin danshen interaction [letter]. Ann Thorac Surg 1999;67:894.

6 Cheng TO. Herbal remedies. Am Fam Physician 1999;60:1661.

7 Cheng TO. The international textbook of cardiology. New York (NY): Pergamon Press; 1987:1067-1070.

\section{Clinicians in private practice give generously in teaching time}

To the Editors,

In his Letter from the Northwest Roberts reflects on the "overpowering greed for money in private practice." ${ }^{1} \mathrm{He}$ states that the clinical decisions made and the ethics of private medicine are primarily driven by dollars. There is little hope, he says, of the academic and private sector sharing their special strengths. Although I agree with his concern over the divide between "town and gown," I do not share his opinion of the greed that he finds in private practice.

Colleagues and I recently completed a survey of clinical faculty who volunteer to teach at one institution (1996-1997) to determine 
the total number of hours contributed by volunteer teaching and administration and to compare this with the number of full-timeequivalent staff. Forty-nine percent of 902 active clinical teachers responded to the survey. Altogether 168,230 hours were contributed by these volunteer teachers during the academic year studied; this corresponds to a total of 81 full-time-equivalent staff. This survey clearly shows that the volunteer clinical faculty were contributing a crucial number of teaching hours to medical students, house officers, and fellows. Those who were surveyed reported that the experience has been a positive one for both students and teachers. Many volunteer faculty have been outstanding role models for their students as is shown by the students' evaluations of their teachers.

Today, both academic centers and those of us in private medicine face great challenges. In some areas, a greater proportion of teaching activity has shifted to the community and is being performed by volunteer clinical faculty. These programs have had little substantive support for this important educational effort. Because of the economic changes brought about by managed care, this important voluntary teaching activity is in danger of extinction. It is imperative that we develop and support the concept of depart- ments of community-based medicine; these can be centers of excellence where community-based education is supported and nourished so that we will ensure the best possible outcome for the future.

Charles M Farr

Association of Clinical Faculty

University of California, San Francisco

7202 N Milbrook, Ste 100

Fresno, CA 93720

References

1 Roberts J. From academia to private medicine: where did the profession go? West J Med 1999;170:308.

\section{ATTENTION MEDICAL WRITERS AND EDITORS}

\section{We are looking for a medical student editor}

The new wjm (Western Journal of Medicine), the preeminent primary care journal, is seeking a Student Editor for the 2000 - 2001 academic year.

The Student Editor will work closely with the editor and editorial staff in developing the monthly journal (both print and electronic) and to develop a vision for a new student section. Candidates should be willing to solicit material and work to edit and prepare the material for publication. Some travel will be involved to West Coast medical schools, to the San Francisco area, and to Europe.

The successful candidate will be provided with a small stipend but, more importantly, will be integrally involved in the editorial process for an innovative medical journal involved in exploring new ways of disseminating educational material in a fun and enjoyable manner to those practicing the art of medicine.

If you have not seen the journal, please visit your medical library to see the print journal and then find us at www.ewjm.com.

Skills necessary:

- team building

- leadership

- creativity

- innovation and thinking outside of traditional domains

- superior writing and communicating skills

- team spirit

- good sense of humor

Criteria:

- senior year medical or other health sciences student

- nomination from a full time Health Sciences faculty member or from the Dean's Office

- letter from a student colleague stating why they feel you would be an ideal candidate

- full curriculum vitae

Send nominations to:

Michael Wilkes, MD, Editor

wjm-western journal of medicine

PO Box 7690

San Francisco, CA 94120-7690

Address questions to Catherine Nancarrow at 〈wjm@ewjm.com〉

The wjm is a peer reviewed, scholarly journal owned and operated by the British Medical Journal, the University of California, San Francisco, and Stanford University. 